To extend their field of readers, the editors have selected some of the articles from their journal which are of particular interest and put them together in book form. These articles have been grouped into twelve 'chapters' and include accounts of recent investigations in astronomy, geophysics, atomic physics, natural evolution, genetics, the nature of viruses, neuro-humoral activities, animal behaviour, the origin of man, neurology, cybernetics and the basis of sensation and perception.

In the main the quality of the book is remarkably high. The editors deserve tribute for the catholicity of their selection, while most of the writers have earned praise for their clarity of presentation. Since this book is intended to provide a survey of contemporary events in the world of science for the general reader, however, it is surprising to find no reference to recent developments in chemotherapy or electronics. General readers would also have welcomed reference to the latest discoveries in artificial fibres which are already doing so much to change the habits of Western man and woman. Even more remarkable is the complete omission of information about those new combinations of metals which are enabling man to build aircraft and other machines which were but dreams some twenty years ago. (It is indeed surprising how so many writers of popular science seem to forget the science of metallurgy, with its overwhelming impact on everyday life. Why?)

In an American book consisting of articles designed mainly for American readers, it is not unexpected that most of the reporting refers mainly to work done by American men of science. An opportunity for popularizing the international character of science may have been lost, however, by the glaring omissions of work being done in other continents. This is all the more peculiar, since many of the American writers of this book began their lives and studies in European and other countries.

Among the outstanding features of a well-written book is a lucid chapter on galaxies in flight by Prof. George Gamow ; a good essay on the military and political implications of the use of the hydrogen bomb by Prof. Hans Bethe; a splendid account of recent researches in geological science by Walter Bucher; and a remarkably clear exposition of the meaning of pain by Prof. W. K. Livingston. A description of experiments in perception by two psychologists is a good example of how science should not be presented to the general reader. The book contains some useful diagrams with valuable explanatory texts. T. H. Hawkins

\section{CHEMISTRY OF HETEROCYCLIC COMPOUNDS}

\section{Condensed Pyridazine and Pyrazine Rings}

(Cinnolines, Phthalazines, and Quinoxalines). By J. C. E. Simpson; pp. xvi $+394 ; 12.50$ dollars.

Imidazole and its Derivatives

Part 1. By Prof. Klaus Hofmann; pp. xviii +448 ; 13.50 dollars.

The Chemistry of Heterocyclic Compounds : a Series of Monographs. (New York : Interscience Publishers, Inc.; London: Interscience Publishers, Ltd., 1953.)

T can scarcely be doubted that progress in hetero1 cyclic chemistry has been hampered by the lack of a comprehensive literature. Defined problems invite and inspire solution; but knowledge, when dispersed or in disarray, conceals its own gaps. The Weissberger series of monographs supplies one means by which the need may be met, and the two volumes here reviewed are respectively the fifth and sixth members of that series. Although in different ways, these volumes commemorate the work of two English chemists : for Dr. J. C. E. Simpson's authoritative writing on the chemistry of cinnolines perpetuates the inspiration he brought to the subject before his untimely death; and Prof. K. Hofmann's book is most fittingly dedicated to F. L. Pyman.

The book by Dr. Simpson is in three sections which correspond to the three types of heterocycle named in the title and include chapters both on the reduced systems and on more highly condensed, polycyclic systems. Each chapter deals with a sub-group of related compounds and is complete with a critical account of preparative methods, general properties and reactions, and a tabulated description of individual compounds, all fully documented. The chemistry of cinnolines and phthalazines is exhaustively covered up to the year 1949. The section on quinoxalines, however, although the largest in the book, omits references which are prior to 1917: for these the reader is referred to the review in Meyer-Jacobson's "Lehrbuch". "This omission does not detract from the intelligibility of the section. Indeed, the whole book is characterized by a lucid and fluent exposition which succeeds in revealing both the chemical interest of the compounds and the gaps in our knowledge concerning them.

The volume on imidazoles (glyoxalines) has two sections, of which the first (pp. 3-324) is the main text of the book and is devoted to a review of funda. mental imidazole chemistry. This is an excellent piece of work. It begins with a résumé of the evidence leading to the current concept of imidazole as a prototropic, highly associated and aromatic structure. There follows, class by class, a critical discussion of synthetic methods and chemical reactions of imidazoles, imidazolines and their derivatives. This is continued for imidazolidines as far as 2-imidazolidones and the corresponding thiones and imides, but at this stage there is an abrupt, unheralded transition to an excellent and comprehensive account of benzimidazoles. Compounds such as hydantoins are thereby omitted and, however expedient this may be, one regrets the break in continuity and unity. It is presumably in accordance with the policy expressed in earlier monographs of the series that imidazole alkaloids are also omitted. These comments do not detract from the value of the material presented. The treatment is sufficiently detailed to reward even the specialist, and yet it maintains a highly readable quality that must commend it to all organic chemists. References are assembled at the end of each chapter, and some of thern relate to work published in 1952 . The second section is a catalogue-comprising names, melting points, melting points of some derivatives and literature references-of all compounds which fall within the same scope and are found in the literature during the period $1919-50$. It is thus in its way a supplement to Beilstein's "Handbuch".

Both volumes are well produced, adequately illustrated by clear structural formulæ and helpfully equipped with subject indexes. In certain places the second volume would benefit, through a less-encumbered text, had superscript numerals been used for references as in the other volume. But this is a small point amid so much that is commendable and welcome.
JAMES D. LoudON 